\title{
STATUS MUTU AIR SUNGAI CIBANTEN BERDASARKAN INDEKS PENCEMARAN AIR
}

\author{
Frebhika Sri Puji Pangesti \\ frebhikasripujipangesti@unbaja.ac.id
}

\begin{abstract}
Sources of pollution, such as settlements, industry, and agriculture are the main sources of river pollution, as is the case with the Cibanten River. The Cibanten River flows across urban areas so that it becomes the focus of attention from various parties. Existing community activities along the river cause a decrease in the water quality of the Cibanten River. Decreased river water quality can be seen physically as well as by monitoring water quality. Based on secondary data from the Department of Environment and Forestry of Banten Province, Cibanten River water quality monitoring was carried out in 6 points starting from Pabuaran Village, PT Telaga Kencana, PT Sumber Mulya Abadi, Serut Village, Kaujon Bridge, and Kaibon Bridge. This research aims to determine water quality status based on physical, chemical and biological parameters and to determine water quality status using the Pollution Index (IP) method. The results of the calculation of Water Quality Status are included in the mild contamination in accordance with the decision of the State Minister for the Environment No. 115 of 2003 concerning the Guidelines for Determination of Water Quality Status, in this study using a Class II water quality classification based on Government Regulation No. 82 of 2001 concerning Management of Water Quality and Pollution Control Water.
\end{abstract}

Keywords : Water quality status, Cibanten River, Pollution Index

\begin{abstract}
Abstrak :Sumber pencemaran,seperti pemukiman,industri, maupun pertanian menjadi sumber utama pencemaran sungai, begitu halnya dengan Sungai Cibanten.Sungai Cibanten mengalir melintasi daerah perkotaan sehingga menjadi pusat perhatian dari berbagai pihak. Aktifitas masyarakat yang ada dibantaran sungai menyebabkan penurunan kualitas air Sungai Cibanten. Penurunan kualitas air sungai dapat dilihat secara fisik maupun dengan pemantauan kualitas air. Berdasarkan data sekunder dari Dinas Lingkungan Hidup dan Kehutanan Provinsi Banten, pemantauan kualitas air Sungai Cibanten dilakukan di 6 titik mulai dari Desa Pabuaran, PT Telaga Kencana, PT Sumber Mulya Abadi ,Kp Serut, Jembatan Kaujon, dan Jembatan Kaibon.Penelitian ini bertujuan untuk mengetahui status mutu air berdasarkan parameter fisika, kimia dan biologi serta untuk menentukan status mutu air dengan metode Indeks Pencemaran (IP). Hasil perhitungan Status Mutu Air termasuk kedalam cemar ringan sesuai dengan keputusan Menteri Negara Lingkungan Hidup Nomor 115 Tahun 2003 tentang Pedoman Penentuan Status Mutu Air,dalam penelitian ini menggunakan klasifikasi mutu air kelas II berdasarkan Peraturan Pemerintah Nomor 82 Tahun 2001 tentang Pengelolaan Kualitas Air dan Pengendalian Pencemaran Air.
\end{abstract}

Kata Kunci : Status Mutu Air, Sungai Cibanten, Indeks Pencemaran 


\section{PENDAHULUAN}

Sungai Cibanten merupakan salah satu sungai yang berada di Kabupaten Serang dan Kota Serang yang dimanfaatkan untuk menunjang kebutuhan pertumbuhan ekonomi.Meningkatnya jumlah penduduk di Kota Serang dan Kabupaten Serang memicu tingginya beban pencemaran di Sungai Cibanten. Aktivitas baik itu dari pemukiman yang berada di bantaran sungai, maupun dari kegiatan industri menjadi penyumbang terbesar yang mengakibatkan penurunan kualitas air Sungai Cibanten. Air yang tercemar di samping dapat mengganggu pertumbuhan dan perkembangan organisme akuatik, juga dapat mengganggu kesehatan masyarakat, karena dapat menimbulkan penyakit bawaan air seperti disentri, gangguan estetika lingkungan seperti menimbulkan bau dan juga tidak sedap dipandang (Yustiani \& Komariah, 2017). Sungai Cibanten memiliki letak yang strategis karena mengalir melintasi wilayah perkotaan, sehingga permasalahan Sungai Cibanten semakin kompleks. Sungai Cibanten juga mengurangi estetika lingkungan karena sebagai tempat pembuangan limbah domestik, limbah rumah sakit, industri,pertanian, peternakan.

Penurunan kualitas air sungai dapat dilihat secara fisik maupun dengan pemantauan kualitas air. Berdasarkan data sekunder dari Dinas Lingkungan Hidup dan Kehutanan Provinsi Banten, pemantauan kualitas air Sungai Cibanten dilakukan di 6 titik mulai dari Desa Pabuaran, PT Telaga Kencana, PT Sumber Mulya Abadi „Kp Serut, Jembatan Kaujon, dan Jembatan Kaibon.Penelitian ini bertujuan untuk mengetahui status mutu air berdasarkan parameter fisika, kimia danbiologi serta untuk menentukan status mutu air dengan metode Indeks Pencemaran (IP).

\section{METODOLOGI PENELITIAN}

\section{Lokasi Pengambilan Sampel}

Penelitian ini dilakukan di Sungai Cibanten Kabupaten Serang yang mempunyai panjang $35 \mathrm{~km}$. Pemantauan air sungai dilakukan di 6 titik lokasi dengan pertimbangan banyaknya potensi sumber pencemaran di titik pemantauan tersebut.Hasil pemantauan kualitas air Sungai Cibanten diperoleh dari data sekunder Dinas Lingkungan Hidup dan Kehutanan Provinsi Banten. Pengambilan sampel dilakukan pada tanggal 23 Juli 2018 sampai dengan 20 September 2018. 
Vol. 1 No.1 Februari 2020

$e$-ISSN : 26228785

$P$-ISSN : 26224984

JURNALIS

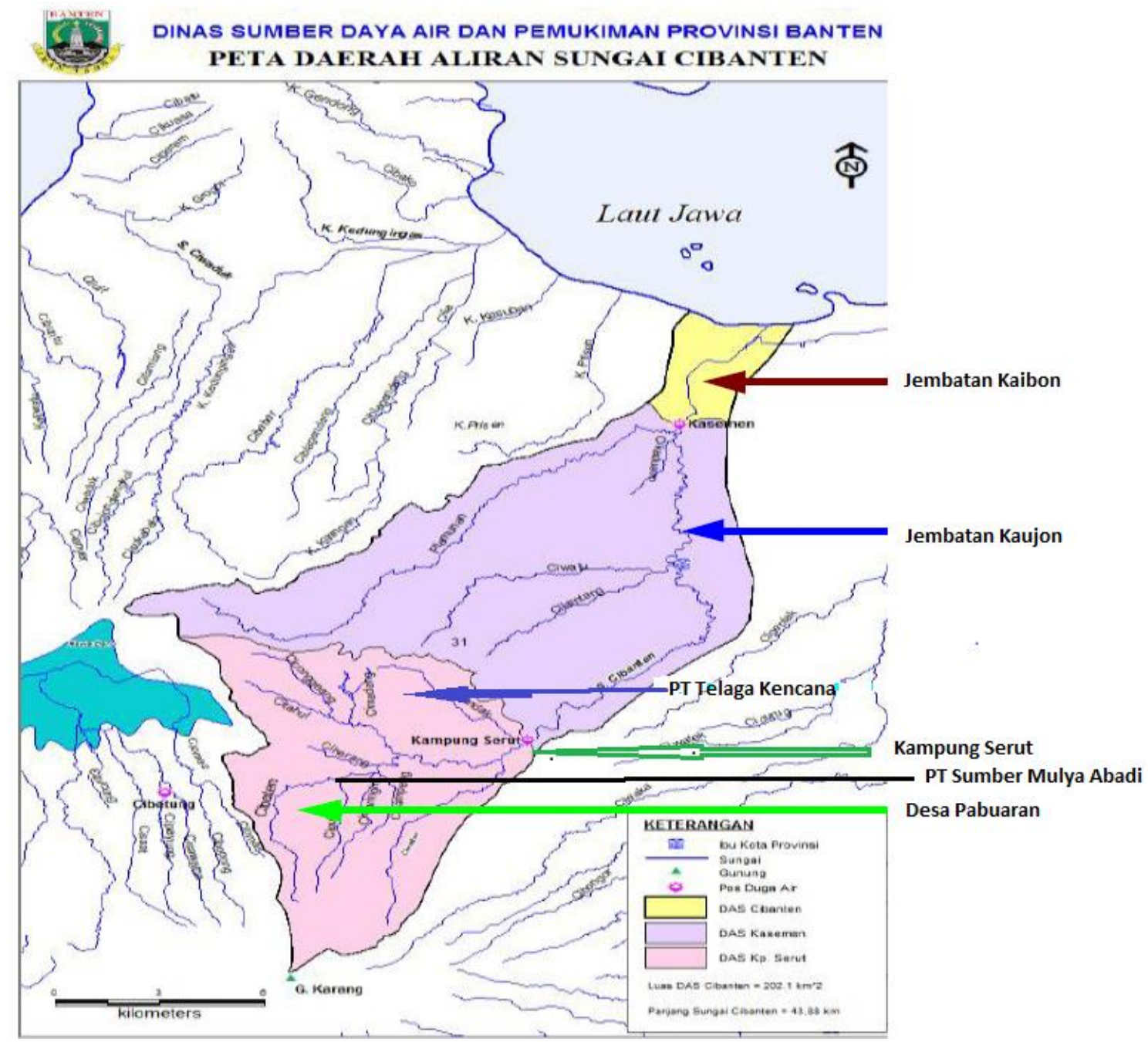

Gambar 1 Peta Titik Pengambilan Sampel

Tabel 1 Titik Pengambilan Sampel Sungai Cibanten

\begin{tabular}{ll}
\hline No & \multicolumn{1}{c}{ Lokasi Pengambilan Sampel } \\
\hline $\mathbf{1}$ & Desa Pabuaran \\
\hline $\mathbf{2}$ & PT Telaga Kencana \\
\hline $\mathbf{3}$ & PT Sumber Mulya Abadi \\
\hline $\mathbf{4}$ & Kp Serut \\
\hline $\mathbf{5}$ & Jembatan Kaujon \\
\hline $\mathbf{6}$ & Jembatan Kaibon \\
\hline
\end{tabular}


Parameter yang diuji antara lain parameter fisika, kimia, dan mikrobiologi dengan mengacu baku mutu kualitas air sungai sesuai dengan Peraturan Pemerintah No 82 Tahun 2001 tentang Pengelolaan Kualitas Air dan Pengendalian Pencemaran Air. Analisis hasil uji kualitas air sungai dibandingkan dengan Baku Mutu Air Kelas II. Penentuan status mutu air dan penentuan Indeks Pencemaran Air (IPA) dihitung sesuai dengan keputusan Menteri Negara Lingkungan Hidup Nomor 115 Tahun 2003 dengan metode indeks pencemaran (Pollution Index $-\mathrm{Pi}$ ) dengan rumus sebagai berikut :

$$
\boldsymbol{P I j}=\sqrt{\frac{\left(\frac{C i}{L i j}\right)_{M}^{2}+\left(\frac{C i}{L i j}\right)_{R}^{2}}{2}}
$$

\section{Keterangan:}

- $\quad \mathrm{Ci} / \mathrm{Lij} \mathrm{M}$ : nilai maksimum dari $\mathrm{Ci} / \mathrm{Lij}$

- $\quad \mathrm{Ci} / \mathrm{Lij} \mathrm{R}$ : nilai rata-rata dari $\mathrm{Ci} / \mathrm{Lij}$

Evaluasi terhadap nilai Pij:

- Memenuhi baku mutu jika $0<\mathrm{Pij}<=1$

- Tercemar ringan jika $1,0<\mathrm{Pij}<=5,0$

- Tercemar sedang jika 5,0 $<\mathrm{Pij}<=10,0$

- Tercemar berat jika Pij > 10,0

Jika Lij menyatakan konsentrasi parameter kualitas air yang dicantumkan dalam Baku Peruntukan Air (j), dan Ci menyatakan konsentrasi parameter kualitas air (i) yang diperoleh dari hasil analisis cuplikan air pada suatu lokasi pengambilan cuplikan dari suatu alur sungai, maka PIj adalah Indeks Pencemaran bagi peruntukan (j) yang merupakan fungsi dari Ci/Lij. Parameter yang dinilai dalam indikator kualitas air yaitu TSS,DO, COD, BOD, Fosfat, Total Coliform dan E.Coli/Fecal Coli.

\section{HASIL DAN PEMBAHASAN}

Analisa Kualitas Air Sungai Cibanten dilakukan di 6 titik pemantauan dengan 7 parameter yang dibandingkan dengan Baku Mutu Kelas II. Baku Mutu Kelas II menurut PP Nomor 82 Tahun 2001 diperuntukkan untuk prasarana/sarana rekreasi air, pembudidayaan ikan air 
tawar, peternakan,air untuk pertanaman, dan atau oeruntukan lain yang mempersyaratkan mutu air yang sama dengan kegunaan tersebut.

Hasil Pengukuran Kualitas Air Sungai Cibanten dari data sekunder tahun 2018 di 6 titik lokasi adalah sebagai berikut :

Tabel 2 Titik Sampling I (Hulu Desa Pabuaran)

\begin{tabular}{|c|c|c|c|c|c|}
\hline \multirow[t]{2}{*}{ No } & \multirow[t]{2}{*}{ Parameter } & \multicolumn{3}{|c|}{ Nilai } & \multirow[t]{2}{*}{ BM Kelas II } \\
\hline & & Maksimum & Minimum & Rata-rata & \\
\hline \multicolumn{6}{|c|}{ A. FISIKA } \\
\hline \multirow[t]{2}{*}{1} & Zat padat tersuspensi (TSS) & 46,1 & 14 & 35 & 50 \\
\hline & $* *)$ & & & & \\
\hline B & KIMIA & & & & \\
\hline 2 & BOD* & 20,14 & 4 & 9 & 3 \\
\hline 3 & COD $* *)$ & 78 & 72 & 74 & 25 \\
\hline 4 & DO* & 2 & 2 & 2 & 4 \\
\hline 5 & Total Phospate $\left(\mathrm{PO}_{4^{-}}\right)$ & 0,4455 & 0,1003 & 0,2154 & 0,2 \\
\hline \multicolumn{6}{|c|}{ C. MIKROBIOLOGI } \\
\hline 6 & Fecal Coliform* & 460 & 460 & 460 & 1000 \\
\hline & Total Coliform* & 5400 & 5400 & 5400 & 5000 \\
\hline
\end{tabular}

Tabel 3 Titik Sampling II (PT Telaga Kencana)

\begin{tabular}{clrrrc}
\hline No & \multicolumn{1}{c}{ Parameter } & & Nilai & & BM Kelas II \\
& & & & & \\
\cline { 3 - 6 } & & Maksimum & Minimum & Rata-rata & \\
\hline A. & FISIKA & & & & \\
\hline $\mathbf{1}$ & $\begin{array}{l}\text { Zat padat tersuspensi (TSS) } \\
\text { **) }\end{array}$ & 4,8 & 4,8 & 4,8 & 50 \\
\hline $\mathbf{B}$ & KIMIA & & & & \\
\hline $\mathbf{2}$ & BOD* & 16,130 & 16,130 & 16,130 & 3 \\
\hline $\mathbf{3}$ & COD $* *)$ & 24,890 & 12,760 & 18,825 & 25 \\
\hline $\mathbf{4}$ & DO* & 3,000 & 3,000 & 3,000 & 4 \\
\hline & & & & & \\
\hline
\end{tabular}




\begin{tabular}{rlrrrl}
\hline $\mathbf{5}$ & Total Phospate $\left(\mathrm{PO}_{4^{-}}\right)$ & 0,469 & 0,082 & 0,275 & \multicolumn{1}{c}{0,2} \\
\hline $\mathbf{C .}$ & MIKROBIOLOGI & & & & \\
\hline $\mathbf{6}$ & Fecal Coliform* & 700 & 700 & 700 & 1000 \\
\hline $\mathbf{7}$ & Total Coliform* & 3500 & 3500 & 3500 & 5000 \\
\hline
\end{tabular}

Tabel 4 Titik Sampling III PT Sumber Mulya Abadi

\begin{tabular}{|c|c|c|c|c|c|}
\hline \multirow[t]{2}{*}{ No } & \multirow[t]{2}{*}{ Parameter } & \multicolumn{3}{|c|}{ Nilai } & \multirow{2}{*}{$\begin{array}{c}\text { BM Kelas } \\
\text { II }\end{array}$} \\
\hline & & Maksimum & Minimum & Rata-rata & \\
\hline A. & FISIKA & & & & \\
\hline 1 & $\begin{array}{l}\text { Zat padat tersuspensi (TSS) } \\
* *)\end{array}$ & 16,25 & 16,25 & 16,25 & 50 \\
\hline $\mathbf{B}$ & KIMIA & & & & \\
\hline 2 & BOD* & 12,13 & 3,59 & 6,437 & 3 \\
\hline 3 & COD $* *)$ & 36,63 & 36,63 & 36,63 & 25 \\
\hline 4 & DO* & 4 & 3 & 3,667 & 4 \\
\hline 5 & Total Phospate $\left(\mathrm{PO}_{4}{ }^{-}\right)$ & 0,917 & 0,100 & 0,372 & 0,2 \\
\hline C. & MIKROBIOLOGI & & & & \\
\hline 6 & Fecal Coliform* & 1400 & 1400 & 1400 & 1000 \\
\hline 7 & Total Coliform* & 35000 & 35000 & 35000 & 5000 \\
\hline
\end{tabular}

Tabel 5 Titik Sampling IV Kampung Serut

\begin{tabular}{clrrrc}
\hline No & \multicolumn{1}{c}{ Parameter } & & Nilai & & BM Kelas \\
& & & & & II \\
\cline { 3 - 6 } & & Maksimum & Minimum & Rata-rata & \\
\hline A. & FISIKA & 15,450 & 12,580 & 13,537 & 50 \\
\hline $\mathbf{1}$ & $\begin{array}{l}\text { Zat padat tersuspensi (TSS) } \\
* *\end{array}$ & & & & \\
\hline $\mathbf{B}$ & KIMIA & & & & \\
\hline $\mathbf{2}$ & BOD* & 25,1 & 25,1 & 25,100 & 3 \\
\hline $\mathbf{3}$ & COD $* *)$ & 65,32 & 15,5 & 32,107 & 25 \\
\hline
\end{tabular}




\begin{tabular}{rlrrrc}
\hline $\mathbf{4}$ & DO* & 3 & 3 & 3 & 4 \\
\hline $\mathbf{5}$ & Total Phospate $\left(\mathrm{PO}_{4^{-}}\right)$ & 0,323 & 0,225 & 0,258 & 0,2 \\
\hline $\mathbf{C .}$ & MIKROBIOLOGI & & & & \\
\hline $\mathbf{6}$ & Fecal Coliform* & 400 & 400 & 400 & 1000 \\
\hline $\mathbf{7}$ & Total Coliform* & 12000 & 12000 & 12000 & 5000 \\
\hline
\end{tabular}

Tabel 6 Titik Sampling V Jembatan Kaujon

\begin{tabular}{|c|c|c|c|c|c|}
\hline \multirow[t]{2}{*}{ No } & \multirow[t]{2}{*}{ Parameter } & \multicolumn{3}{|c|}{ Nilai } & \multirow{2}{*}{$\begin{array}{c}\text { BM Kelas } \\
\text { II }\end{array}$} \\
\hline & & \multirow[t]{2}{*}{ Maksimum } & \multirow[t]{2}{*}{ Minimum } & \multirow[t]{2}{*}{ Rata-rata } & \\
\hline A. & FISIKA & & & & \\
\hline 1 & Zat padat tersuspensi (TSS) & 3,880 & 3,880 & 3,880 & 50 \\
\hline & $* *)$ & & & & \\
\hline $\mathbf{B}$ & KIMIA & & & & \\
\hline 2 & BOD* & 15,120 & 5,800 & 8,907 & 3 \\
\hline 3 & $\mathrm{COD} * *)$ & 29,140 & 24,870 & 27,717 & 25 \\
\hline 4 & DO* & 2,000 & 2,000 & 2,000 & 4 \\
\hline 5 & Total Phospate $\left(\mathrm{PO}_{4-}\right)$ & 0,472 & 0,275 & 0,341 & 0,2 \\
\hline & MIKROBIOLOGI & & & & \\
\hline 6 & Fecal Coliform* & 150 & 150 & 150 & 1000 \\
\hline 7 & Total Coliform* & 3500 & 3500 & 3500 & 5000 \\
\hline
\end{tabular}

Tabel 7 Titik Sampling VI Jembatan Kaibon

\begin{tabular}{|c|c|c|c|c|c|}
\hline \multirow[t]{2}{*}{ No } & \multirow[t]{2}{*}{ Parameter } & \multicolumn{3}{|c|}{ Nilai } & \multirow{2}{*}{$\begin{array}{c}\text { BM } \\
\text { Kelas } \\
\text { II }\end{array}$} \\
\hline & & Maksimum & Minimum & Rata-rata & \\
\hline A. & FISIKA & & & & \\
\hline 1 & Zat padat tersuspensi $(\mathrm{TSS}) * *)$ & 17,350 & 17,350 & 17,350 & 50 \\
\hline $\mathbf{B}$ & KIMIA & & & & \\
\hline 2 & BOD* & 15,130 & 15,130 & 15,130 & 3 \\
\hline
\end{tabular}




\begin{tabular}{|c|c|c|c|c|c|}
\hline 3 & COD $* *)$ & 25,360 & 15,100 & 18,520 & 25 \\
\hline 4 & DO* & 3,000 & 3,000 & 3,000 & 4 \\
\hline 5 & Total Phospate $\left(\mathrm{PO}_{4-}\right)$ & 0,103 & 0,015 & 0,074 & 0,2 \\
\hline C. & MIKROBIOLOGI & & & & \\
\hline 1 & Fecal Coliform* & 350 & 350 & 350 & 1000 \\
\hline 3 & Total Coliform* & 15000 & 15000 & 15000 & 5000 \\
\hline
\end{tabular}

Dari hasil pemantauan kualitas air sungai Cibanten untuk parameter Fisik ,nilai TDS rata-rata sudah memenuhi baku mutu, parameter kimia yaitu BOD, COD dan DO, dari ke 6 (enam) titik sampling tersebut sebagian besar melebihi baku mutu air Kelas II , hal ini karena beban limbah rumah tangga yang masuk ke sungai sangat tinggi, yaitu melebihi $25 \mathrm{ppm}$ untuk parameter COD dan $3 \mathrm{ppm}$ untuk parameter BOD. Hasil parameter biologi yaitu Total Coliform menunjukkan di beberapa titik diatas baku mutu yaitu, di bagian hulu (Desa Pabuaran), PT Sumber Mulya Abadi, Kampung Serut dan Jembatan Kaibon, sedangkan untuk parameter Fecal Coliform ada satu titik sampling yang melebihi baku mutu yaitu di PT Sumber Mulya Abadi.

\section{Penentuan Status Mutu Air Sungai Cibanten dengan Indeks Pencemaran}

Metode penentuan Status Mutu Air menggunakan Indeks Pencemaran. Indeks pencemaran digunakan untuk menentukan tingkat pencemaran relatif terhadap parameter kualitas air yang diijinkan (Nemerow 1974). Penilaian terhadap kualitas badan air yang sesuai dengan peruntukannya dengan Indeks Pencemaran (IP) sebagai bentuk pengelolaan kualitas air apabila terjadi penurunan kualitas badan air akibat adanya senyawa pencemaran. Berikut adalah rekapitulasi nilai PIj dari 6 titik Pantau di Sungai Cibanten:

Tabel 8 Hasil Perhitungan IP Status Mutu Air Sungai Cibanten

\begin{tabular}{llllll}
\hline No & Lokasi & $\mathrm{Ci} / \mathrm{LijR}$ & $\mathrm{Ci} / \mathrm{LijM}$ & $\mathrm{PIj}$ & Keterangan \\
\hline 1. & Desa Pabuaran & 1,47 & 3,39 & 2,6 & Cemar Ringan \\
\hline 2. & PT Telaga Kencana & 1,28 & 4,65 & 3,4 & Cemar Ringan \\
\hline 3. & PT Sumber Abadi & 2,06 & 5,23 & 4,0 & Cemar Ringan \\
\hline 4. & Jembatan Kaujon & 1,16 & 3,36 & 2,5 & Cemar Ringan \\
\hline
\end{tabular}




\begin{tabular}{llllll}
\hline 5. & Jembatan Kaibon & 1,43 & 4,51 & 3,3 & Cemar Ringan \\
\hline 6. & Kampung Serut & 1,80 & 5,61 & 4,2 & Cemar Ringan \\
\hline
\end{tabular}

Dari Hasil perhitungan menunjukan IP Sungai Cibanten dari 6 Lokasi Pengambilan Sampel relatif sama yaitu berstatus tercemar ringan. Hal ini dikarenakan skor IP yang berada pada rentang $1,0<\mathrm{PIj} \leq 5,0$.

\section{KESIMPULAN}

1. Hasil penelitian menunjukkan bahwa parameter kimia sebagian besar melebihi baku mutu air kelas II sesuai dengan PP No.82 Tahun 2000. Parameter BOD tertinggi terdapat di titik sampling Telaga Kencana yaitu sebesar 16,13 ppm, sedangkan parameter DO tertinggi ada di titik sampling PT Sumber Mulya Abadi sebesar 36,63 ppm.

2. Parameter biologi

Parameter Faecal coli tertinggi terdapat di PT Sumber Mulya Abadi yaitu sebesar 1400 ppm, begitu juga dengan parameter Total Coliform nilai tertinggi berada pada hasil sampling di PT Sumber Mulya Abadi yaitu sebesar 35000 ppm.

3. Dari hasil perhitungan Status Mutu Air termasuk kedalam cemar ringan sesuai dengan keputusan Menteri Negara Lingkungan Hidup Nomor 115 Tahun 2003 menyatakan bahwa sungai dikategorikan tercemar ringan apabila $1,0<\mathrm{Pij}<=5,0$

\section{DAFTAR PUSTAKA}

Asuhadi,Sunarwan.,\&Abdul

Manan.(2018).Status Mutu

Air Pelabuhan

Panggulubelo Berdasarkan

Indeks Storet dan Indeks

Pencemaran.Jurnal

Kelautan

Nasional,Vol.12,No.2.
Baherem, B., Suprihatin, S., \& Indrasti, N. S. (2014). Strategi Pengelolaan Sungai Cibanten Provinsi Banten Berdasarkan Analisis Daya Tampung Beban Pencemaran Air dan Kapasitas Asimilasi. Jurnal Pengelolaan Sumber Daya 
Alam dan Lingkungan,

Vol.4, No. 1.

Dinas Lingkungan Hidup dan

Kehutanan Provinsi

Banten.2017. Laporan

Pemantauan Kualitas Air

Sungai Cibanten 2017.

Keputusan Menteri Negara

Lingkungan Hidup Nomor

115 Tahun 2003.Pedoman

Penentuan Status Mutu Air.

Kementerian Lingkungan

Hidup

dan

Kehutanan.Jakarta.

Nemerow N.L,1974.Industrial

Waste Pollution,

London,Addison Wesley

Publishing Company.

Paramadyasta, A. 2011. Studi

Penelitian Status Mutu Air

dengan Metode STORET

dan Indeks Pencemaran di

Waduk Sutami. Skripsi.

Jurusan Pengairan Fakultas

Teknik Universitas

Brawijaya.

Yustiani, Y. M., \& Komariah, I. (2017). Investigation on the Biodegradation Capacity of Urban Rivers in Jakarta, Indonesia. International
Journal of Geomate, Vol.12,

Issue 34: 45-50 